\title{
Efficacy of Anti-VEGF and Subtenon Injection of Triamcinolone Acetonide for Choroidal Neovascularization Associated with Multifocal Choroiditis
}

\author{
Dongning Liu, Cong Zhang, Li Xu* \\ The Fourth People's Hospital of Shenyang, Shenyang, China \\ Email: liudongning1976@126.com,cong_zhang25@hotmail.com, *xu-li1149@163.com
}

How to cite this paper: Liu, D.N., Zhang, C. and Xu, L. (2017) Efficacy of Anti-VEGF and Subtenon Injection of Triamcinolone Acetonide for Choroidal Neovascularization Associated with Multifocal Choroiditis. Open Journal of Ophthalmology, 7, 117-123.

https://doi.org/10.4236/ojoph.2017.72016

Received: February 28, 2017

Accepted: May 15, 2017

Published: May 18, 2017

Copyright $\odot 2017$ by authors and Scientific Research Publishing Inc. This work is licensed under the Creative Commons Attribution International License (CC BY 4.0).

http://creativecommons.org/licenses/by/4.0/

\begin{abstract}
Purpose: To evaluate the short-term efficacy of intravitreal anti-VEGF (Lucentis) and sub-tenon injection of triamcinolone acetonide for choroidal neovascularization (CNV) associated with multifocal choroiditis (MC). Methods: Eight eyes of 8 patients treated with intravitreal anti-VEGF and posterior sub-tenon injection of Triamcinolone Acetonide (TA) for subfoveal or juxtafoveal $\mathrm{CNV}$ associated with $\mathrm{MC}$ were retrospectively reviewed. Best corrected visual acuity (BCVA), results of fundus fluorescein angiography (FFA)/indocyanine green angiography (ICGA), optical coherence tomography (OCT) at baseline and 3, 6 months after treatment were compared. Results: All of the 8 patients showed significant improvement in BCVA at 3 and 6 months after treatment $(\mathrm{P}<0.05)$. FFA/ICGA showed decrease or cessation of inflammation in 8 patients (100\%). 7 patients (87.5\%) had no significant active leakage while 1 patient (12.5\%) had persistent leakage from the neovascular lesion at 3-month follow up. 6 months after treatment, no recurrence of inflammation occurred and no active leakage in all 8 patients. OCT showed reduced CNV area and alleviated edema. There are no severe treatment-related side effects expect slight eye pain during infusion in one patient. Intraocular pressure was all normal in follow up. Conclusion: Although the follow-up time and the number of patients in this study were limited, the use of intravitreal antiVEGF combined with sub-tenon injection of TA was associated with improvement of visual acuity in patients with CNV secondary to MC. Further studies including a greater number of patients with longer follow up time are needed.
\end{abstract}

\section{Keywords}

Anti-VEGF, Tenon Injection of TA, Multifocal Choroiditis, CNV 


\section{Introduction}

Multifocal choroiditis (MC) is a relatively uncommon idiopathic chorioretinitis which was firstly reported by Nozik and Dorsch Eli in 1973 [1]. It is characterized in most cases by multiple punched-out choroidal spots in association with signs of vitreous and anterior chamber inflammation [2] [3]. Visual acuity impairment may depend on several causes including cystoid macular edema, CNV and scarring of the fovea. The occurrence of CNV is the most frequent cause of visual loss [4] [5]. There are no proven methods of treating CNV associated with MC. Recent studies showed that sub-tenon injection of corticosteroids has been successful in causing regression of CNV in some patients. However, many patients still have CNV after corticosteroids treatment alone. Anti-VEGF treatment has been showed to be effective in destroying CNV with almost no injury to the retina [6]. In this article, we retrospectivey reviewed the efficacy of combined intravitreal anti-VEGF and sub-tenon injection of TA in treating CNV in 7 patients with MC at our clinic.

\section{Patients and Methods}

\subsection{Patients}

We retrospectively reviewed the medical records of 8 eyes of $8 \mathrm{MC}$ patients, who received intravitreal anti-VEGF and sub-tenon injection of TA between May, 2012 and July, 2014. Each patient underwent slitlamp microscopy, FFA/ICGA and OCT examination. Blood examination had been performed to exclude the other infections, for example syphilis and tuberculosis. All the 8 patients were diagnosed as subfoveal or juxtafoveal CNV second to the MC. Seven patients were female and 1 was male with a mean age of 35 years (range 31 - 43 years). The baseline BCVA ranged from $0.05-0.2$ ( 0.11 on average).

Inclusion criteria were: 1) Presence of signs of anterior uveitis in the acute phase, detection of multifocal chorioretinal lesions situated in the posterior pole and periphery which was diagnosed as MC. 2) Evidence of subfoveal or juxtafoveal CNV. 3) No fundus photocoagulation, intraocular drug injection or intraocular surgury treatment history in the study eye. 4) The inflammation had been controlled for three months.

Exclusion criteria were: 1) severe refracting media opacity complications such as severe cataract, keratopathy, vitreous hemorrhage which will affect ocular fundus examination and treatment; 2) severe hypertension, diabetes mellitus and impaired cardiac, pulmonary and renal function; 3) tuberculosis infection.

The potential risks and benefits were discussed with all patients before they received treatment, and each patient read and signed an informed consent form.

\subsection{Combination Therapy}

After intravitreal lucentis $(0.05 \mathrm{ml}, 0.5 \mathrm{mg})$ injection, $2 \mathrm{ml} \mathrm{TA}(50 \mathrm{mg} / 5 \mathrm{ml})$ was delivered via sub-tenon injection after routine sterilization and topical anesthesia. All the patients had only one session combination therapy. 
BCVA was measured using the Early Treatment Diabetic Retinopathy Study (ETDRS) chart at baseline and 3, 6 months after treatment. Ocular anterior segment/fundus examinations as well as FFA/ICGA and OCT were also performed at baseline and 3, 6 months after treatment.

\subsection{Statistical Analysis}

The BCVA was performed statistical analysis (ANOVA) using SPSS 11.5 (SPSS, Inc., Chicago, IL). $\mathrm{P}<0.05$ was considered as statistically significant.

\section{Results}

\subsection{BCVA and Ocular Anterior Segment/Fundus Examination}

The mean BCVA was $0.06 \pm 0.02,0.38 \pm 0.11$ and $0.42 \pm 0.09$ before and 3,6 months after treatment. BCVA at 3 and 6 months after treatment had significantly improved compared with baseline $(\mathrm{P}<0.05)$ while the differences of BCVA between 3 and 6 months was not significant $(\mathrm{P}>0.05)$.

Ocular anterior segment examination showed 3 patients with vitreous opacity and 1 patient with inflammation of iris at baseline and resolution of the inflammation and significant reduction of vitreous opacity at 3, 6 months after treatment. Fundus examination showed multifocal round or oval yellow-grey chorioretinal lesions situated in the posterior pole and/or the periphery before treatment and round atrophic lesion with variable depigmentation 3, 6 months later.

\subsection{FFA/ICGA/OCT}

FFA/ICGA showed window defect where atrophic lesions situated 1 month after treatment and the decrease of leakage from CNV (Figure 1(a) and Figure 1(b)) in 7 patients (87.5\%) and persistent leakage in 1 patient (12.5\%). After treatment for 6 months, there is no recurrence of inflammation and all the patients had decrease or stoppage of leakage from CNV. OCT showed reduced CNV area and alleviated tissue edema after 6 months treatment (Figure 2(a) and Figure 2(b)).

\subsection{Adverse Events}

There were no serious treatment-related adverse events in all patients expect 1 complaining of slight eye pain during which disappeared right after the administration. There were no systemic adverse events.

\section{Discussion}

MC is a kind of chronic and recurrent chorioretinitis. The typical fundus examination shows there are scattered grey-yellow lesions situated in the posterior pole or mid-periphery. About 1/3 of the patients with MC have CNV. The neovascularization associated exudation and bleeding will lead to RPE or neuroretinal detachment and finally disc-scar formation [7].

The cause of MC is not clearly understood. It is reported to be associated with viral infection, or other infection diseases such as tuberculosis or syphilis [8]. 


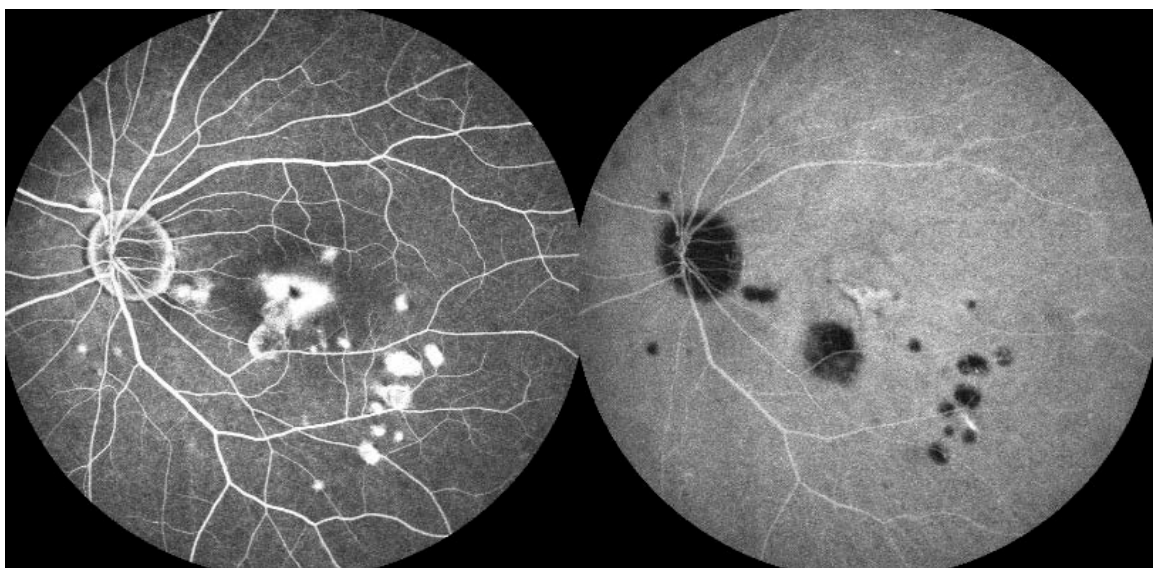

(a)

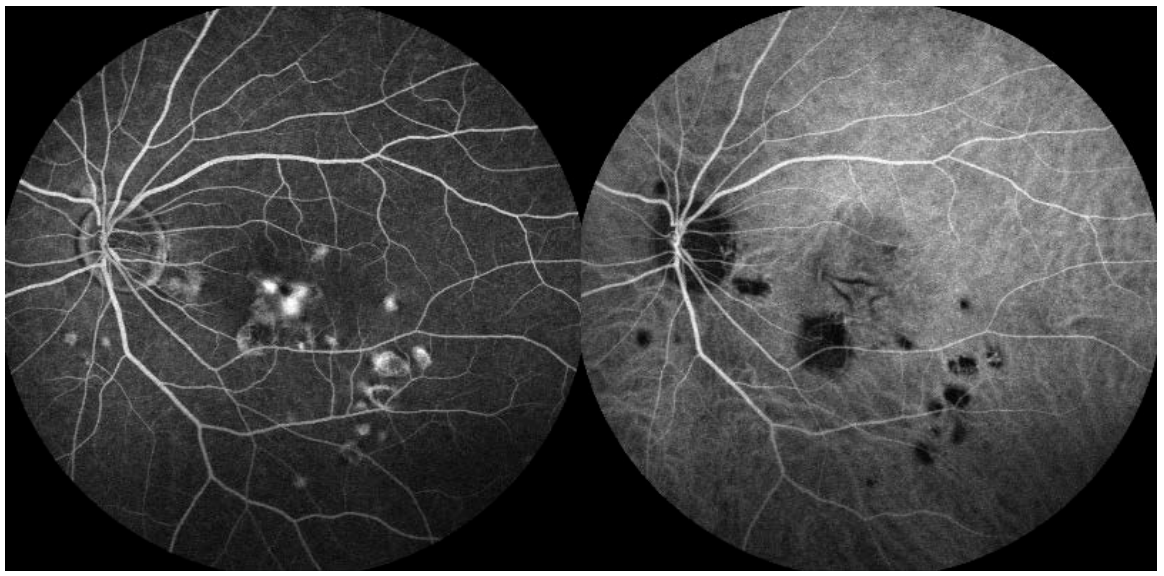

(b)

Figure 1. FFA/ICGA images of pre-treatment and 6-month treatment. (a) The leakage from $\mathrm{CNV}$ is obvious before treatment. (b) The leakage from $\mathrm{CNV}$ is decreased after 6-month treatment.

There is no proven therapy for MC. The common treatment modality such as immunosuppressive agents and corticosteroids can be successful in treating inflammation of MC with limited efficacy in associated CNV [9]. Current therapies for $\mathrm{CNV}$ include laser photocoagulation, surgery, PDT and intravitreal anti-VEGF. Both laser photocoagulation and PDT can cause severe vision loss in subfoveal CNV and recurrence of CNV is common [10]. Surgery did not increase the chance of stable of improved visual acuity, and was associated with a high risk of rhegmatogenous retinal detachment.

After introduction of anti-VEGF agents, many investigators have reported the efficacy of anti-VEGF monotherapy or combined therapy with PDT for exudative AMD [11] [12] [13] [14].

In this study, we evaluated one session of intravitreal lucentis combined with posterior sub-tenon injection of TA for CNV secondary to MC. We found that during the 6-month follow up, all the patients treated had significant improvement of BCVA. FFA/ICGA showed stoppage or decrease of anterior and fundus inflammation as well as leakage from CNV. OCT showed reduced CNV area and 


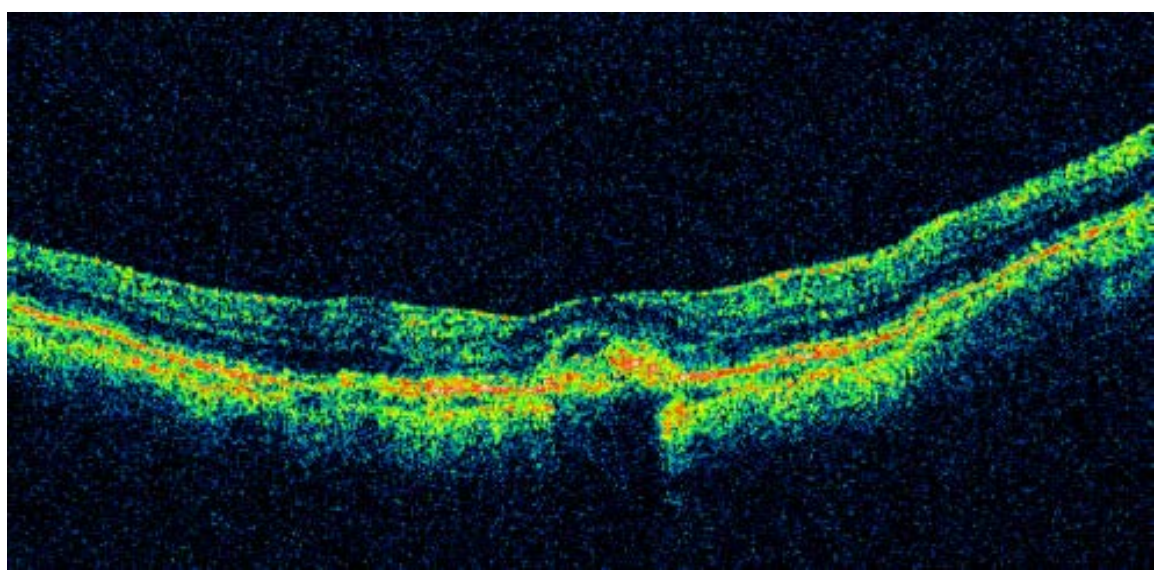

(a)

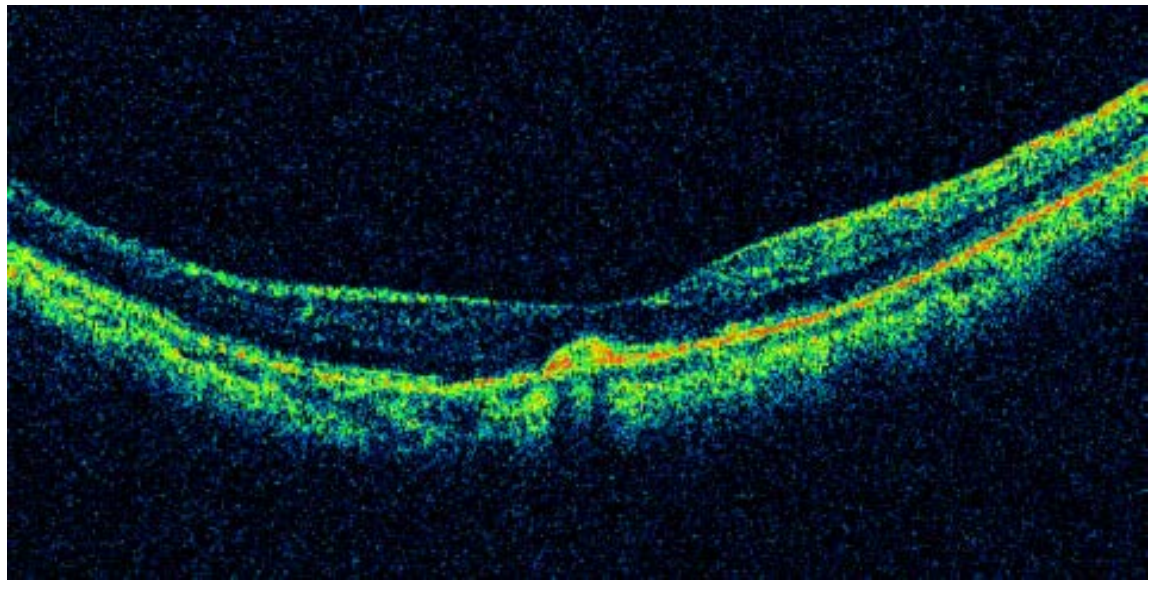

(b)

Figure 2. OCT images of pre-treatment and 6-month treatment. (a) OCT shows CNV and macular edema before treatment. (b) CNV area and macular edema are reduced after 6-month treatment.

alleviated tissue edema. No patient had severe treatment-related side effects.

The present study has important limitations including its retrospective nature, small sample size, short follow-up time and lack of a control group. However, the positive results of the study and the absence of treatment-related side effects suggest that intravitreal anti-VEGF combined with sub-tenon injection of TA may be considered as a safe and effective treatment option for CNV secondary to MC for a 6-month period. Further studies are necessary to confirm the preliminary results and to improve current treatment modalities.

\section{Conclusion}

Here, we presented the case reports of combined therapy for patients with CNV secondary to MC. Although the follow-up time and the number of patients in this study were limited, the use of intravitreal anti-VEGF combined with subtenon injection of TA was associated with improvement of visual acuity in patients with CNV secondary to MC. Further studies including a greater number of patients with longer follow up time are needed. 


\section{Declaration}

\section{Availability of Data and Materials}

All the data supporting the findings is contained within the manuscript.

\section{Authors Contributions}

L. X. drafted the manuscript and participated in the design of the study. D. N. L. participated in the design of the study and helped to draft the manuscript. C. Z. was involved in the analysis and interpretation of data. All authors reviewed and approved the final manuscript.

\section{Competing Interests}

The authors declare that they have no competing interests.

\section{Consent to Publish}

Not applicable.

\section{Ethics Approval and Consent to Participate}

This study was approved by the Forth People's Hospital of Shenyang and conformed to the provisions of the Declaration of Helsinki.

Written informed consent was obtained from the patients for publication of this case report and any accompanying images. A copy of the written consent is available for review by the editor-in-chief of this journal.

\section{References}

[1] Nozik, R.A. and Dorsch, W. (1973) A New Chorioretinopathy Associated with Anterior Uveitis. American Journal of Ophthalmology, 76, 758-762. https://doi.org/10.1016/0002-9394(73)90573-4

[2] Thorne, J.E., Wittenberg, S., Jabs, D.A., et al. (2006) Multifocal Choroiditis with Panuveitis Incidence of Ocular Complications and of Loss of Visual Acuity. Ophthalmomogy, 113, 2310-2316.

[3] Siakter, J.S., Giovannini, A., Yannuzzi, L.A., et al. (1997) Indocyanine Green Angiography of Multifocai Choroiditis. Ophthalmology, 104, 1813-1819. https://doi.org/10.1016/S0161-6420(97)30022-0

[4] Dreyer, R.F. and Gass, J.D.M. (1984) Multifocal Choroiditis and Panuveitis: A Syndrome That Mimics Ocular Histoplasmosis. Archives of Ophthalmology, 102, 1776 1784. https://doi.org/10.1001/archopht.1984.01040031440019

[5] Li, D. and Kishi, S. (2007) Loss of Photoreceptor Outer Segment in Acute Zonal Occult Outer Retinopathy. Acta Ophthalmologica, 125, 1194-1200. https://doi.org/10.1001/archopht.125.9.1194

[6] Schenck, F. and Boke, W. (1990) Retina1 Vasculitis with Multifocalretinochoroiditis. International Ophthalmology, 14, 401-404. https://doi.org/10.1007/BF00163566

[7] Tiedeman, J.S. (1987) Ebstein-Barr Viral Antibodies in Multifocal Choroiditis and Panuveitis. American Journal of Ophthalmology, 103, 659-663. https://doi.org/10.1016/S0002-9394(14)74325-9 
[8] Michel, S.S., Ekong, A., Baltatzis, S., Foster, C.S., et al. (2002) Multifocal Choroiditis and Panuveitis: Immunomodulatory Therapy. Ophthalmology, 109, 378-383. https://doi.org/10.1016/S0161-6420(01)00901-0

[9] Vianna, R.N.G., Özdal, P.Ç., Filho, J.P.S., et al. (2004) Longterm Follow-Up of Patients with Multifocal Choroiditis and Panuveitis. Acta Ophthalmologica, 82, 748753. https://doi.org/10.1111/j.1600-0420.2004.00343.x

[10] Avery, R.L., Pieramici, D.J., Rabena, M.D., et al. (2006) Intravitreal Bevacizmab (Avastin) for Neovascular Age-Related Macular Degeneration. Ophthalmology, 113, 363-372. https://doi.org/10.1016/j.ophtha.2005.11.019

[11] Gomi, F., Sawa, M., Sakaguchi, H., et al. (2008) Efficacy of Intravitreal Bevacizumab for Polypoidal Choroidal Vasculopathy. British Journal of Ophthalmology, 92, 7073. https://doi.org/10.1136/bjo.2007.122283

[12] Song, J.H., Byeon, S.H., Lee, S.C., et al. (2009) Short Term Safety and Efficacy of a Single Intravitreal Bevacizumab Injection for the Management of Polypoidal Choroidal Vasculopathy. Ophthalmologica, 223, 85-92. https://doi.org/10.1159/000175312

[13] Rich, R.M., Rosenfeld, P.J., Pliafito, C.A., et al. (2006) Short-Term Safety and Efficacy of Intravitreal Bevacizumab (Avastin) for Neovascular Age-Related Macular Degeneration. Retina, 26, 495-511. https://doi.org/10.1097/01.iae.0000225766.75009.3a

[14] Bashshur, Z.F., Bazarbachi, A., Schakal, A., et al. (2006) Intravitreal Bevacizumab for the Management of Choroidal Neovascularization in Age-Related Macular Degeneration. American Journal of Ophthalmology, 142, 1-9.

https://doi.org/10.1016/j.ajo.2006.02.037

\section{Abbreviatons}

MC, multifocal choroiditis; CNV, choroidal neovascularization; BCVA, best corrected visual acuity; FFA, fundus fluorescein angiography; ICGA, indocyanine green angiography; OCT, optical coherence tomography; VEGF, vascular endothelial growth fractor; TA, triamcinolone acetonide.

Submit or recommend next manuscript to SCIRP and we will provide best service for you:

Accepting pre-submission inquiries through Email, Facebook, LinkedIn, Twitter, etc. A wide selection of journals (inclusive of 9 subjects, more than 200 journals)

Providing 24-hour high-quality service

User-friendly online submission system

Fair and swift peer-review system

Efficient typesetting and proofreading procedure

Display of the result of downloads and visits, as well as the number of cited articles

Maximum dissemination of your research work

Submit your manuscript at: http://papersubmission.scirp.org/

Or contact ojoph@scirp.org 